\title{
ON COLOUR REACTIONS OF DIBASIC ACIDS OF FATTY SERIES, ESPECIALLY OF FUMARIC ACID.
}

\author{
By Teizo Takahasmi and Kinichiro Sakaguchi.
}

(Received June 28th., 1926.)

On the colour reaction of fumaric acid as far as we know just one ${ }^{(1)}$ is acpuainted with to give a red colouration when the acid is reacted with diazobenzenesulphonic acid. However the delicacy of it is not sufficient enough to be relied upon as a sole reaction. The colour reactions described below offer a more satisfactory means of identification.

\section{First REACTION.}

As the reagents required are resorcinol and sulphuric acid, the procedure is already known in the case of succinic acid. ${ }^{(2)}$

A piece of fumaric acid of the size of a pin's head is placed in a test tube with about ten times its quantity of powdered resorcinol and 1-1.5 c.c. of concentrated sulphuric acid then heated gently in the beginning and later briskly until it attains nearly $190-195^{\circ} \mathrm{C}$. Whereby the liquid becomes red with a green fluorescence. After cooling add some water and heat again.

Cool well and a few drops of the reaction products are introduced drop by drop into ammonia, which colours red with a green fluorescence.

This reaction is to be given by the dilute solution of fumaric acid, thus :A few drops of a $0.1 \%$ solution of fumaric acid placed in a test tube with equal drops of a 0.1 per cent solution of resorcinol and 1-1.5 c.c. of concentrated sulphuric acid gives a liquid which on treating as mentioned above shows a yellow colour with green fluorescence.

Anhydride: i. e. maleinic anhydride gives quite the same colouration as met with by crystals of fumaric acid.

Succinic acid gives a yellow colouration in the first part of the reaction and when introduced into ammonia it changes to a green fluorescent liquid.

Malic acid on treating as above gives a liquid which on heating becomes at first yellow and then crimson-red even after the addition of water. A blueish violet colour is produced by adding 2 or 3 drops of this crimson-red colour fluid into ammonia.

This colouration is quite specific to malic acid and may distinguish this

(1) Hans Finbeck : Zeit. f. Phys. Chem. Bd. 90, S. 306, 1914.

(2) L. Rosenthaler : Nachweis Org. Verb. S. 331. 
from succinic- and fumaric acids.

Tartaric acid. Mohler's reaction ${ }^{(3)}$ for the detection of the acid is analogous to ours in applying the same reagents, although we applied a higher temperature than in his case. ${ }^{(4)}$. No fluorescence is observed when the reaction product is added to ammonia.

Citric acid. Our reaction is a new one to this acid. On treating the crystals of citric acid of the size of a pea as in the case of tartaric acid a liquid is obtained which on heating becomes at first pink-red and then yellow by a prolonged heating. Pink-red colour recovers when it is diluted with water. Finally when a few drops of the liquid is added to ammonia the latter takes a blueish-green fluorescence with violet shade, this is specific to the citric acid.

Beside these dibasic acids gluconic-, mucic-, saccharic-, and lactic acids behave in a very similar way. These reactions will be described in the other paper.

\section{SECOND REACTION. ${ }^{(5)}$}

This is based on the colour produced when the acid to be tested is reacted with $\alpha$-naphtol in the presence of concentrated sulphuric acid.

The procedure is quite same as it is mentioned in the first reaction, where resorcinol is used.

Fumaric acid. This acid gives a green colour when the reagents are just mixed. By gently heating it becomes at first yellow then pink-red and finally brown-red which changes to an opaque brown liquid after a long standing. Red colour is restored by the addition of water to the liquid. When this liquid, after shaking is introduced drop by drop into ammonia a yellow-green colouration is perceived. After standing the reddish shade intensifies with fluorescence.

The change of reaction given by the other acids will be shown in the table below :-

$$
\text { Acid. When they are }
$$

Succinic acid.

$$
\text { Green. }
$$

Dark and light red.

Crimson-red and
Malic acid.

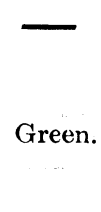

Citric acid. it alters to spaque fluid.

Tartaric acid (Pinêrūa's reaction :Fırst blue then green)

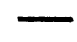

Yellow $\rightarrow$ light pink red yellow $\rightarrow$ greenish blue

$$
\text { Green } \rightarrow
$$
crimson-red. by addition of water
Colour produced

by ammonia.

Light greenishyellow with fluorescence.

Red with fluorescence.

Iight yellow.

Pink red. 


\section{THIRD ReAction.}

In this case $\beta$-naphtol is used instead of $\alpha$-naphotl employed in the second reaction. The first part of this reaction is already demonstrated by Pinêrŭa ${ }^{(6)}$ to detect citric acid, which gives a blue color according to his description. For citric acid however the delicacy of the reaction is not sufficient enough as we have experienced with fumaric acid.

A small piece of fumaric acid of the size of pin's head is put in a test tube with $\beta$-naphtol and sulphuric acid.

The yellowish-green mixture on heating first colorless then dark-red and finally turns to a dark-green opaque liquid. After cooling and diluting with water, the red color goes into the aqueous layer leaving a green layer underneath it. On shaking the green color is restored with fluorescence which increases when the liquid is added to ammonia.

The colourations given by the other acids by this reagent are tabulated below :-

\begin{tabular}{|c|c|c|c|c|}
\hline Acid. & $\begin{array}{l}\text { When they } \\
\text { are mixed. }\end{array}$ & On heating. & $\begin{array}{l}\text { By adding } \\
\text { water. }\end{array}$ & $\begin{array}{l}\text { Colour given } \\
\text { by ammonia. }\end{array}$ \\
\hline Succinic acid. & $\begin{array}{l}\text { Yellowish- } \\
\text { light green } \\
\text { colouration }\end{array}$ & $\begin{array}{l}\text { Becomes } \\
\text { colourless then } \\
\text { dark violet } \\
\text { and finally } \\
\text { greenish violet } \\
\text { (Less delicate than } \\
\text { fumaric acid). }\end{array}$ & $\begin{array}{l}\text { Water } \\
\text { colours } \\
\text { yellow. }\end{array}$ & $\begin{array}{l}\text { Green } \\
\text { fluorescent } \\
\text { fluid. }\end{array}$ \\
\hline Malic acid. & $\begin{array}{l}\text { Colourless or } \\
\text { light green- } \\
\text { ish yellow. }\end{array}$ & $\begin{array}{l}\text { From light yellow- } \\
\text { ish to red. A } \\
\text { fluorescence while } \\
\text { yellow. (Distinction } \\
\text { from lactate). }\end{array}$ & Red. & $\begin{array}{l}\text { Light yellow } \\
\text { with fluorescence. }\end{array}$ \\
\hline Tartaric acid. & Colourless. & $\begin{array}{c}\text { First green then } \\
\text { to dark bluish- } \\
\text { green. }\end{array}$ & $\begin{array}{l}\text { Darkness } \\
\text { increases. }\end{array}$ & $\begin{array}{l}\text { Coloured yellow } \\
\text { with fluorescence. }\end{array}$ \\
\hline Citric acid. & & $\begin{array}{l}\text { Light dark blue. } \\
\text { Green after } \\
\text { cooling. (Blue } \\
\text { after Piñerūa). }\end{array}$ & $\begin{array}{l}\text { Becomes } \\
\text { yellowish. }\end{array}$ & $\begin{array}{l}\text { Light green } \\
\text { with fluorescence. }\end{array}$ \\
\hline
\end{tabular}

\section{Fourth REACTION.}

This reaction is given by hydroquinone and sulphuric acid. The reaction is quite same as in the foregoing reactions. Fumaric acid gives no color

(3) Mohler's reaction: Bull. Soc. chim. France [3] 4 (1890), 728.

(4) Mohler heated to $130^{\circ} \mathrm{C}$, but in our case it should be heated to $190-195^{\circ} \mathrm{C}$.

(5) Pinêrūa's (1897) Colour reaction of tartaric acid which becomes first blue then green when reacted with $\alpha$-naphtol and sulphuric acid. 
just when the reagents are mixed. On heating gently at first a light-red then a dark-red color appears. By the addition of water it changes to yellow. The end color reaction given when the product is added to ammonia is yellow. This reaction is especially preferable to identify succinic acid from fumaric acid which accompanies the former as an impurity.

Following table shows a distinction of colors given by the other acids :-

\begin{tabular}{|c|c|c|c|c|}
\hline Acid. & $\begin{array}{l}\text { When they } \\
\text { are mixed. }\end{array}$ & On heating. & $\begin{array}{l}\text { By adding } \\
\text { water. }\end{array}$ & $\begin{array}{l}\text { Colour given } \\
\text { by ammonia. }\end{array}$ \\
\hline Succinic acid. & Colourless. & $\begin{array}{l}\text { First yellow } \\
\text { then dark green } \\
\text { (Distinction from } \\
\text { fumaric acid.) }\end{array}$ & $\begin{array}{c}\text { Dark- } \\
\text { yellow. }\end{array}$ & $\begin{array}{l}\text { Fluorescent } \\
\text { yellowish-green } \\
\text { (Distinction from } \\
\text { fumaric acid.) }\end{array}$ \\
\hline Malic acid. & Colourless. & $\begin{array}{l}\text { First yellow } \\
\text { then blood red. }\end{array}$ & $\begin{array}{l}\text { Redness } \\
\text { increases. }\end{array}$ & Dirty yellow. \\
\hline Tartaric acid. & Colourless. & $\begin{array}{l}\text { First yellow } \\
\text { with evolution of } \\
\text { gas, then reddish- } \\
\text { yellow and finally } \\
\text { crimson red. }\end{array}$ & - & Orange yellow. \\
\hline Citric acid. & Colourless. & $\begin{array}{l}\text { Yellow at first } \\
\text { then dark green. }\end{array}$ & & $\begin{array}{l}\text { Yellowish-green } \\
\text { with fluorescence. }\end{array}$ \\
\hline
\end{tabular}

\section{Summary.}

1) The first reaction given by dibasic acid of fatty series in the presence of resorcinol and concentrated sulphuric acid, is a quite new one as to the fumaric acid.

Fumaric acid gives red-color with green fluorescence and by this color is distinguishable from succinic acid which gives just a green fluorescence by the same treatment.

The colourations given by malic, tartaric and citric acids distinguish them from each other most conveniently.

2) The color reaction given by $\alpha$-naphtol and concentrated sulphuric acid (second reaction) is a new one for fumaric acid (green to red). Succinic acid shows less delicacy than fumaric acid. So it is most conveniently advisable to use this reaction for the identification of either fumaric or succinic acid, especially when the former is present in succinic acid as an impurity. Tartaric acid gives no fluorescence in the last colouration in this reaction as experienced in the first reaction. Citric acid may be distinguished from other acid only by the absence of fluorescence in the last colour.

3) Green colour with fluorescence given by fumaric acid in presence of $\beta$-naphtol and sulphuric acid is a new reaction as far as related to this acid. As to succinic, malic, tartaric and citric acids the colouration given by the same procedure is quite specific to each of these acids. The distinction of 
succinic acid from fumaric exists in the purplish tinge by the former in the stage of heating in the procedure. Both malic and tartaric acids distinguish from fumaric, succinic and citric acids by the fluorescent light yellow colouration in the end of the reaction. Malic acid characterizes itself from tartaric acid by a yellowish-red or a fluorescent yellow colour in the stage of heating and a red colour by the addition of water in the procedure i. e. the colouration due to the latter is dark bluish-green on heating and dark when diluted with water.

4) The fourth colour reaction given by fumaric acid in presence of hydroquinone and sulphuric acid is a new one with regard to this acid. By the same procedure succinic acid gives a fluorescent yellowish-green colouration which is easily recognisable even accompanied with yellow colour to be produced by fumaric acid if present as an impurity. Malic, tartaric and citric acids show a very delicate and characteristic colouration by this procedure.

(This is reported already in "Journal of the Agric. Chemic. Society of Japan." Vol.

No. 14, 1925.1)

\title{
ON THE PRESENCE OF THE URIC ACID IN THE PUPA OF TUSSAH SILKWORM
} (ANTHEREA PERNYI).

\author{
By Jiro KaTo. \\ (From the (entral Laboratory, S. M. R. Co. Dairen, Sorth Manchuria.)
}

(Received Aug. 9th., 1926.)

There are many researches on the chemical constitution of silkworm at different stages of its metamorphosis, but no research on tussah silkworm. So we tried to study the chemical constitution of the pupa of tussah silkworm; and learned that the pupa contains a tolerably large quantity of uric acid. We determined its uric acid content by estimating the soluble matter, soluble nitrogen, and uric acid form nitrogen at the different stages of pupa, and the uric acid content was found to be about $1 \%$ at the beginning and $4 \%$ at the end.

As tussah silkworm passes a winter in the pupa stage, this stage durates about 200 days and the metabolism is carried on without taking food. Therefore, one can imagine that there is increase of the uric acid content in the pupa body as experienced in this work. It is very interesting as a new 